\title{
Brief Physician Advice For High-Risk Drinking Among Young Adults
}

\author{
Paul M. Grossberg, $M D^{1}$ \\ David D. Brown, $P b D^{2}$ \\ Michael F. Fleming, $M D, M P H^{2}$ \\ 'Department of Pediatrics, University \\ of Wisconsin, Madison, Wis \\ ${ }^{2}$ Department of Family Medicine, \\ University of Wisconsin, Madison, Wis
}

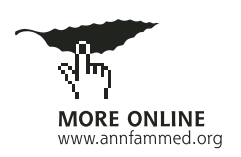

\begin{abstract}
BACKGROUND High-risk alcohol use in persons 18 to 30 years of age is a critical public health problem. It is the number 1 cause of death in this population. This article reports the results of a subanalysis of young adults (aged 18 to 30 years) who participated in Project TrEAT (Trial of Early Alcohol Treatment) conducted in the offices of 64 primary care physicians located in 10 counties in southern Wisconsin.
\end{abstract}

METHODS Project TrEAT was a randomized clinical trial designed to test the efficacy of a brief intervention protocol to reduce alcohol use, improve health status, and decrease health care utilization. A total of 226 young adults were randomly assigned to either a usual care or brief intervention group.

RESULTS There were no significant differences between the 2 groups at baseline on a number of potential confounders. During the 4-year follow-up period, there were significant reductions in number of persons drinking more than 3 drinks per day, average 7-day alcohol use, number of persons drinking 6 or more drinks per occasion, and number of binge drinking episodes in the previous 30 days $(P<.01$ to $P<.001)$. There were also significant differences $(P<.05)$ in emergency department visits (103 vs 177), motor vehicle crashes (9 vs 20), total motor vehicle events (114 vs 149), and arrests for controlled substance or liquor violation (0 vs 8 ).

CONCLUSION In this 4-year subanalysis of young adults who participated in Project TrEAT, we found long-term reductions in high-risk drinking behaviors and consequences. The findings of this study support more widespread implementation of brief interventions in primary care settings.

Ann Fam Med 2004;2:474-480. DOI: 10.1370/afm.122

\section{INTRODUCTION}

$\mathrm{H}$ igh-risk drinking in young adults (aged 18 to 30 years) is a critical public health problem. Binge drinking (more than 4 to 5 drinks per occasion) and heavy alcohol use (more than 2 to 3 drinks per day) is associated with motor vehicle crashes, injuries, violence, spinal cord trauma, tobacco use, illicit drug use, depression, suicide, unwanted sexual experiences, and a variety of adverse societal effects. ${ }^{1}$ National surveys estimate 10,500 persons aged 15 to 24 years and 11,500 adults aged 25 to 34 years die from alcohol-related causes each year. Hingson et $\mathrm{al}^{3}$ calculate 1,500 college students die every year from alcohol-related trauma and motor vehicle crashes. Alcohol-related mortality remains the most common cause of death in young adults, and morbidity rates have changed little in the last decade. ${ }^{4}$ Thus, the prevention and treatment of alcoholrelated harm has become a national priority.

One intervention designed to reduce alcohol-related harm is brief counseling delivered within health care settings. ${ }^{5}$ There have been more than 100 studies reported in the literature, as well as a number of metaanalyses, examining the efficacy of brief intervention in clinical settings. ${ }^{6,7}$ Although none of the studies focused exclusively on young adults 18 to 30 years of age, a number of studies were conducted with college students 
and older adolescents. ${ }^{8}$ In 1 randomized controlled trial conducted with 348 college students at the University of Washington, Marlatt et $\mathrm{al}^{9}$ found significant reductions in alcohol use in the group that participated in a single cognitive behavioral counseling session combined with written feedback.

The goal of this article is to report the results of a subanalysis of 226 young adults aged 18 to 30 years who participated in Project TrEAT. ${ }^{10,11}$ This report presents 48-month follow-up data on changes in high-risk drinking, emergency departments visits, motor vehicle crashes, and illegal consequences.

\section{METHODS}

Project TrEAT was a randomized clinical trial designed to test the efficacy of brief physician advice in reducing alcohol use, improving health status, and reducing health care utilization and costs. A total of 774 patients were randomly assigned to usual care or the experimental brief intervention group. Of these patients, 226 were between the ages of 18 and 30 years. The intent of this report is to review the results in this young adult sample. Previous publications have reported results from the overall sample measured at 6 to 48 months. ${ }^{10,11}$

Potential study participants were approached as they checked in for a regular appointment in the offices of 64 primary care clinicians in 17 primary care clinics located in 10 counties in southern Wisconsin. The sites ranged from cities with a population of less than 2,500 to a large urban metropolitan area. Primary inclusion criteria focused on male patients who drank more than 14 drinks per week or female patients who drank more than 11 drinks per week in the previous 90 days. The 64 participating physicians were required to be practicing full-time in community primary care practices and board certified in family medicine or internal medicine.

The patients were asked to complete a Health Screening Survey (HSS) as they checked in with the receptionist. The HSS contained questions on the frequency of exercise, weight control, tobacco use, alcohol use, mental health issues, drug use, and socioeconomic information. ${ }^{12}$ A researcher assigned to the clinic reviewed the survey questionnaires, contacted by telephone those patients who were positive for at-risk alcohol use, and invited them to participate in a faceto-face 30-minute interview that included additional health status and health care utilization questions. Alcohol use was assessed using a 30-day timeline follow-back procedure. ${ }^{13}$ Patients eligible for the study were randomized to usual care or scheduled to see their physicians for a brief intervention.

The brief intervention by the physician consisted of 2 short counseling sessions 4 weeks apart. Each 10- to 15-minute face-to-face counseling session was offered in the context of routine patient care during which the physician used a scripted workbook. The intervention workbook included a review of alcohol-related health effects, a pie chart displaying the frequency of different types of at-risk drinkers, a list of methods to cut down drinking, a treatment contract, and cognitive behavioral exercises. An office nurse contacted the patients 2 and 8 weeks after the initial counseling sessions to reinforce the face-to-face sessions. Previous publications describe the intervention in greater detail. ${ }^{10,11}$

Follow-up telephone interviews were conducted at $6,12,24,36$, and 48 months after the intervention to gather patient data on alcohol use, health status, and health care utilization. Researchers conducting the interviews were blinded to whether participants were in the brief intervention or usual care group. A collaborative family member interview was conducted at 12 months after the intervention. The collaborative interview found that family members consistently reported less alcohol use than the participants reported. Additional outcomes of interest, including legal events, such as drunk-driving citations, road crashes, injuries, and arrests, were obtained from the Wisconsin Department of Transportation and the Crime Information Bureau of the Wisconsin Department of Justice. Self-report and health care claims data were also obtained to assess the frequency of emergency department visits and days of hospitalizations during the 48 -month follow-up period.

\section{Statistical Analysis}

We used repeated measures analysis of variance ${ }^{14}$ to determine significance of the overall treatment effect and time-related trends in alcohol use, health status, and health care utilization. The repeated measures design involves a nested variance structure in which sources of variation at the patient level include treatment status and patient sex; within-patient variability includes time interval, time-treatment interaction, and time-sex interaction. The $P$ values at individual followup points were determined by contrasting the timetreatment interaction term at each time interval with the baseline time-treatment interaction. The overall treatment effect was calculated as a baseline vs postbaseline contrast of all time-treatment interactions.

As in the 12 -month report, ${ }^{10}$ data from patients randomized to the experimental group who failed to complete the intervention visits were analyzed on an intent-to-treat basis. When no follow-up data were available, alcohol use measures for patients were imputed using the baseline measure. This imputation provided a conservative estimate of effect size, as most patients reduced alcohol consumption from baseline levels. Patient data that were missing from some but 
not all of the follow-up reports were imputed using post-baseline averages. In all, 99\% $(n=223)$ of the patients participated in at least 1 follow-up interview, and $88 \%$ completed the follow-up interviews at 6,12 , 24, 36 and 48 months.

\section{RESULTS}

A total of 4,861 young adult patients between 18 and 30 years of age completed the Health Screening Survey (HSS). Of these patients, 850 (17\%) had a screening result that was positive for at-risk alcohol use and were invited to participate in a face-to-face assessment interview at their physician's office. Of the 503 (59\%) young adults who consented to participate further in the study and who completed the face-to-face assessment, 226 (45\%) met all criteria for the trial and were randomized to either the experimental $(n=114)$ or control group $(\mathrm{n}=112)$. Most of the patients who failed to meet inclusion criteria reported 7-day alcohol use that was less than the selected cutoff limit or did not want to participate because of consent issues. The timeline follow-back procedure ${ }^{14}$ used in the face-toface assessment interview to gather information on daily alcohol use provided more accurate information than the quantity or frequency questions on the HSS. To increase its sensitivity, the HSS was designed to overestimate weekly alcohol use. Other reasons for exclusion included moving out of the area, recent suicide ideation, alcohol dependence, alcohol treatment in the previous year, and severe medical problems.

Table 1 displays data from the HHS on 4,861 per- sons aged 18 to 30 years visiting 1 of 17 primary care offices for routine health care. These persons were seeking care from 1 of the 64 primary care physicians who participated in the study.

A supplemental table, which is available online at http://www.annfammed.org/cgi/content/ full/2/5/474/DC1, compares the young adults randomly assigned to the control $(\mathrm{n}=112)$

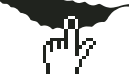
and experimental $(n=114)$ groups, with no significant difference $(P<.05)$ on any baseline measure, including sex, age, education, marital status, household size, ethnicity, income, tobacco use, and mental health. Other measures not listed in this supplemental table, which also suggest random distribution of potential confounding factors, included baseline alcohol use measures, medical problems, medications, emergency department visits, trauma, road crashes, sleep disorders, drug use, alcohol-related arrests, and traffic events.

Follow-up rates were high in this young adult subsample and similar to those reported in the full TrEAT study. ${ }^{11}$ Almost all $(97 \%, \mathrm{n}=220)$ of the young adults participated in the 12 -month follow-up interview, $93 \%(\mathrm{n}=210)$ in the 24 -month review, 93\% $(\mathrm{n}=$ $210)$ in the 36 -month review, and $88 \%(\mathrm{n}=199)$ in the 48-month review. Reasons why 27 (12\%) did not participate through the 48 -month interview include 1 alcohol-related death, 11 refusals to participate, and 15 lost to follow-up.

\section{Changes in Alcohol Use}

Changes in 4 measures of alcohol use are displayed in Table 2. Measures include number of participants who

Table 1. Results of Health Screening Survey (HHS) in a Sample of Young Adults ( $n=4,861$ ) Who Completed the HSS While Waiting to See Their Primary Care Physician

\begin{tabular}{|c|c|c|c|c|c|c|}
\hline Characteristics & $\begin{array}{c}\text { Male } \\
18-25 \text { y } \\
(n=717) \\
\%(n)\end{array}$ & $\begin{array}{c}\text { Female } \\
18-25 y \\
(n=1,743) \\
\%(n)\end{array}$ & $\begin{array}{c}\text { Male } \\
26-30 y \\
(n=755) \\
\%(n)\end{array}$ & $\begin{array}{c}\text { Female } \\
26-30 y \\
(n=1,646) \\
\%(n)\end{array}$ & $\begin{array}{c}\text { Total } \\
\text { (n }=4,861) \\
\%(n)\end{array}$ & $\begin{array}{c}\text { Student } \\
(n=793) \\
\%\end{array}$ \\
\hline \multicolumn{7}{|l|}{ Alcohol use } \\
\hline 0 drinks & $28(201)$ & $33(568)$ & 25 (189) & $34(555)$ & $31(1513)$ & 33 \\
\hline 1-7 drinks & 27 (192) & $43(752)$ & $31(236)$ & $44(718)$ & 39 (1898) & 39 \\
\hline 8-14 drinks & $24(174)$ & $17(291)$ & $27(200)$ & $17(276)$ & $19(941)$ & 18 \\
\hline 15 or more drinks & $21(150)$ & 8 (132) & $17(130)$ & $6(97)$ & $11(509)$ & 10 \\
\hline \multicolumn{7}{|l|}{ Binge drinking* } \\
\hline 0 times in past $30 \mathrm{~d}$ & $48(336)$ & $71(1217)$ & $50(372)$ & 74 (1201) & $65(3126)$ & 67 \\
\hline $1-2$ times in past $30 \mathrm{~d}$ & $25(176)$ & $20(344)$ & $27(196)$ & $20(324)$ & $22(1040)$ & 21 \\
\hline 3-4 times in past $30 \mathrm{~d}$ & $12(82)$ & $6(97)$ & $12(91)$ & $4(72)$ & $7(342)$ & 7 \\
\hline 5 or more in times past $30 \mathrm{~d}$ & 15 (109) & $3(57)$ & $11(80)$ & $2(35)$ & $6(281)$ & 5 \\
\hline \multicolumn{7}{|l|}{ Cigarette use } \\
\hline Yes & $34(241)$ & $33(569)$ & $32(243)$ & $32(528)$ & $33(1581)$ & 23 \\
\hline Lifetime & 92 & 39 & 35 & 37 & 36 & \\
\hline
\end{tabular}


drank more than 3 drinks per day, average 7 -day alcohol use, number of participants drinking 6 or more drinks per occasion in the previous 30 days, and frequency of binge drinking in the previous 30 days. There were statistically significant reductions in alcohol use between groups for all 4 measures during the 48 -month period $(P<.01$ to $P<.001)$. Most change in alcohol use in both groups occurred in the first 6 months after randomization. The experimental group decreased their use by $40 \%$ to $50 \%$ at the 6 -month follow-up interview and the control group decreased by $15 \%$ to $20 \%$. Alcohol use reductions in the experimental group remained stable during the 48 -month follow-up period.

\section{Table 2. Primary Outcome: Changes in Alcohol Use Between Groups} After Brief Intervention ( $\mathrm{N}=226$ )

\begin{tabular}{|c|c|c|c|c|}
\hline Alcohol Use & $\begin{array}{c}\text { Treatment } \\
\mathrm{n}=114 \\
\%(\mathrm{n})\end{array}$ & $\begin{array}{c}\text { Control } \\
n=112 \\
\%(n)\end{array}$ & t Score & $P$ Value \\
\hline \multicolumn{5}{|l|}{$\begin{array}{l}\text { Consumes } \geq 3 \text { drinks per } \\
\text { day in previous } 7 \text { days }\end{array}$} \\
\hline Baseline & $39(45)$ & $46(51)$ & 0.92 & NS \\
\hline $6 \mathrm{mo}$ & $18(20)$ & $30(34)$ & 2.08 & .02 \\
\hline $12 \mathrm{mo}$ & $17(19)$ & $35(39)$ & 2.98 & .002 \\
\hline $24 \mathrm{mo}$ & $14(16)$ & $30(34)$ & 2.80 & .01 \\
\hline $36 \mathrm{mo}$ & $14(16)$ & $35(39)$ & 3.53 & .001 \\
\hline $48 \mathrm{mo}$ & $15(17)$ & $20(22)$ & 0.70 & NS \\
\hline \multicolumn{5}{|l|}{ Overall $P<.001^{*}$} \\
\hline Drinks consumed in & Mean No. (SD) & Mean No. (SD) & & \\
\hline $\begin{array}{l}\text { previous / days } \\
\text { Baseline }\end{array}$ & & & 136 & \\
\hline Daseinte & $10.2(11.2)$ & $10.3(12.1)$ & 1.50 & IV \\
\hline $6 \mathrm{mo}$ & $9.4(10.3)$ & $14.3(11.1)$ & 3.42 & .001 \\
\hline $12 \mathrm{mo}$ & $8.8(8.8)$ & $15.0(13.2)$ & 4.10 & .001 \\
\hline $24 \mathrm{mo}$ & $8.9(9.5)$ & $14.5(16.6)$ & 3.16 & .002 \\
\hline $36 \mathrm{mo}$ & $9.4(12.7)$ & $13.9(16.3)$ & 2.32 & .02 \\
\hline $48 \mathrm{mo}$ & $8.6(10.2)$ & $11.6(12.7)$ & 1.91 & .06 \\
\hline \multicolumn{5}{|l|}{ Overall $P<.002^{*}$} \\
\hline Binge drinking in the & $\%(n)$ & $\%(n)$ & & \\
\hline $\begin{array}{l}\text { previous } 30 \text { days } \\
\text { Baseline }\end{array}$ & $96(110)$ & 96 (107) & 0.37 & NS \\
\hline $6 \mathrm{mo}$ & $6(76)$ & $84(94)$ & 3.04 & .01 \\
\hline $12 \mathrm{mo}$ & $6(75)$ & $88(99)$ & 4.08 & .001 \\
\hline $24 \mathrm{mo}$ & $76(87)$ & $85(95)$ & 1.64 & NS \\
\hline $36 \mathrm{mo}$ & $70(80)$ & $76(85)$ & 1.00 & NS \\
\hline $48 \mathrm{mo}$ & $66(75)$ & 81 (91) & 2.66 & .01 \\
\hline \multicolumn{5}{|l|}{ Overall $P<.01 *$} \\
\hline Episodes of binge drinking & Mean No. (SD) & Mean No. (SD) & & \\
\hline Baseline & $5.9(4.0)$ & $6.3(4.3)$ & 0.78 & NS \\
\hline $6 \mathrm{mo}$ & $3.1(4.5)$ & $4.9(4.7)$ & 2.90 & .01 \\
\hline $12 \mathrm{mo}$ & $2.9(3.7)$ & $5.3(4.8)$ & 4.17 & .001 \\
\hline $24 \mathrm{mo}$ & $4.2(4.9)$ & $5.6(5.1)$ & 2.17 & .03 \\
\hline $36 \mathrm{mo}$ & $4.2(5.7)$ & $5.5(6.5)$ & 1.55 & NS \\
\hline $48 \mathrm{mo}$ & $3.6(4.7)$ & $4.8(5.5)$ & 1.72 & .08 \\
\hline Overall $P<.01^{*}$ & & & & \\
\hline
\end{tabular}

The reduction in alcohol use in the control group was stable from 6 to 36 months and dropped again at 48 months. A reduction in use by the control group has been a consistent observation in most brief intervention trials $\mathrm{s}^{6-8}$ and may be related to the intervention effect of the follow-up procedures, the regression to the mean phenomenon, or natural history of alcohol use in community samples. The additional drop in the control group at 48 months may be related to substantive developmental maturity that occurs in young adults as they grow older.

Figure 1, which is available online only and can be found at http://www.annfammed.org/cgi/ content/full/2/5/474/

DC1, illustrates changes in the percentage of participants drinking more than 3 drinks per day. Members of this group are identified as heavy drinkers and are at greatest risk for alcoholrelated problems. The number of heavy drinkers in the treatment group decreased from 45 (39\%) to 20 participants (18\%) during the follow-up period, a $55 \%$ reduction in the percentage of heavy drinkers. A significant statistical difference between groups was maintained through 36 months.

Figure 2, available online only at http://www.ann fammed.org/cgi/content/ full/2/5/474/DC1, illus-

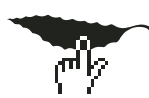
trates the significant differences in 7-day alcohol use between the usual care controls and the brief intervention group during the 4year follow-up period. The overall significance of the treatment effect for mean number of drinks per week using repeated measures analysis of variance ${ }^{13}$ was $P<.001$. The experimental group reduced their alcohol use from an average of 16.2 drinks per week at baseline to 9.4 drinks per week at the 6-month follow-up interview ( $42 \%$ reduction in use) and generally maintained this level of use for 48 months. As shown in Figure 2, the control group also reduced their use but not as much as the treatment group. 


\begin{tabular}{|c|c|c|}
\hline Outcomes & $\begin{array}{l}\text { Treatment } \\
(n=114) \\
\text { No. of Events (\%) }\end{array}$ & $\begin{array}{l}\text { Control } \\
(\mathrm{n}=112) \\
\text { No. of Events (\%) }\end{array}$ \\
\hline \multicolumn{3}{|l|}{ Medical use (48 mo after baseline) } \\
\hline Emergency department visits* & $103(48)$ & $177(63)$ \\
\hline Days of hospitalization & $131(28)$ & $150(17)$ \\
\hline \multicolumn{3}{|l|}{ Motor vehicle events (48 mo after baseline) } \\
\hline Motor vehicle crash with fatalities & 0 & 1 \\
\hline Motor vehicle crash with nonfatal injuriest & 9 & 20 \\
\hline Motor vehicle crash with property damage only & 19 & 28 \\
\hline Operating while intoxicated & 8 & 10 \\
\hline Other moving violations & 78 & 81 \\
\hline Total motor vehicle events ${ }^{\dagger}$ & $114(55)$ & $149(67)$ \\
\hline \multicolumn{3}{|l|}{ Legal events (48 mp after baseline) } \\
\hline Assault, battery, child abuse & 6 & 6 \\
\hline Resist or obstruct office, disorderly conduct & 6 & 3 \\
\hline Controlled substance, liquor violation* & 0 & 8 \\
\hline Criminal damage, property damage & 1 & 3 \\
\hline Theft, robbery & 1 & 3 \\
\hline Other arrests & 2 & 3 \\
\hline Total legal events & $16(11)$ & $26(11)$ \\
\hline \multicolumn{3}{|c|}{$\begin{array}{l}\text { Note: nonparametric comparisons of events in treatment vs control using binomial distribution. The values in } \\
\text { parentheses indicate the number of individuals involved. A single individual may have been involved in multiple } \\
\text { events. }\end{array}$} \\
\hline \multicolumn{3}{|c|}{$* P<.01$} \\
\hline
\end{tabular}

\section{DISCUSSION}

We report positive results from a randomized controlled trial of a brief intervention conducted in a sample of young adults 18 to 30 years. It is the first report to show long-term reductions in alcohol use, emergency department visits, motor vehicle accidents, and legal events in young adults. Limitations of previous studies included small samples, short-term followup, brief counseling by research therapists, an absence of intention-to-treat procedures, lower follow-up rates, and an inability to show changes in multiple outcome measures. ${ }^{7-9,15}$

Strengths of the current study include a randomized clinical trial that successfully distributed known confounders. The study was conducted in 17 primary care practices of 64 full-time family physicians and internists. The intervention was delivered by the patient's physician rather than a research-trained therapist or psychologist. The sites included rural medium-sized cities and large urban communities. By using embedded health behavior questions, the control participants were unaware of the primary focus of the study. More than $95 \%$ of the participants, when asked at a follow-up interview, believed the study was about general health issues. The study had high follow-up rates, with more than $98 \%$ of the participants attending at least one follow-up interview, primarily because of the accessibility of the patients, whose physicians were in stable, community-based primary care practices. More than 90\% of the participants or their parents were employed and had health insurance. This study is the only one reporting participant follow-up for 4 years or using claims data and public records to assess changes in health status and legal events.

Our study findings confirm results from previous work on brief counseling and alcohol use in other populations. ${ }^{7,8}$ Brief interventions are time-limited, patientcentered counseling strategies that focus on changing behavior and increasing compliance with health recommendations. Our results suggest that if physicians spend a few focused minutes talking with their patients, $40 \%$ to $50 \%$ will change their alcohol use behavior and reduce risk for alcohol-related adverse events. In 
the larger context of patient care, the study supports the notion that brief counseling can change a variety of health behaviors, including alcohol use, smoking, ${ }^{16,17}$ exercise ${ }^{18}$ high-risk sexual behaviors, ${ }^{19}$ and possibly nutrition and medication compliance. ${ }^{20}$

Brief counseling is one the most important therapeutic modalities used by physicians. Principles that correlate with success in changing behavior include using a practiced combination of empathic, patientcentered questions, appropriate pauses, attentive body language, and congruent verbal and nonverbal messages. Specific brief intervention procedures may include, but are not limited to, (1) assessment and direct feedback ("As your physician, I am concerned about how much you drink and how it is affecting your health"); (2) behavioral modification techniques ("Here's a list of situations when people drink and sometimes lose control of their drinking. Where do you think you fit in, and how can you avoid these situations?") $)_{i}(3)$ contracting and goal setting ("You need to cut down on your drinking. What do you think about cutting down to 3 drinks, 2 or 3 times per week? What is a realistic goal you can commit to in improving your health?" with the goal written on a prescription pad); and (4) self-help-directed bibliotherapy. ${ }^{21,22}$

Project TrEAT used a combination of motivational interviewing, cognitive behavioral therapy, and physician-directed counseling. These sessions, which took only 10 to 15 minutes of the physician's time twice in 1 month, can be incorporated relatively easily into a primary care practice. Alcohol-screening tools can be given to patients and briefly reviewed by nursing and medical assistant staff, in a manner similar to tobacco screening. The physician can then use brief intervention techniques to begin the process of long-term behavior change.

Project TrEAT was an efficacy study. It was not designed to test changes in physician practice behavior with problem drinkers. During follow-up interviews with physicians who participated in Project TrEAT, however, we found that they incorporated a number of elements of the intervention protocol into their practices. Effectiveness studies are needed to determine how to change physician practice behavior with patients who drink above recommended limits.

This 4-year subanalysis of young adults who participated in Project TrEAT found long-term reductions in high-risk drinking behaviors and adverse events. Considering the striking morbidity and mortality from high-risk drinking, it is encouraging that practicing physicians can address this health care priority in a cost-efficient and clinically effective manner. This study supports the widespread implementation of brief interventions in primary care practices and in settings that serve young adults, such as high school and college health clinics. Incorporating brief intervention strategies to reduce high-risk drinking in young adults is a critical priority for all primary care providers.

To read or post commentaries in response to this article, see it online at http://www.annfammed.org/cgi/content/full/2/5/474.

Key words: Alcohol drinking; substance-abuse screening; primary health care; delivery of health care; health services research; patient education: brief intervention.

Submitted September 24, 2003; submitted, revised, December 17, 2003; accepted December 29, 2003.

Funding support: This study was supported by National Institutes of Health, AA08512-01A and the Robert Wood Johnson Foundation.

\section{References}

1. Department of Health and Human Services, PHS, NIH, National Institute on Alcohol Abuse and Alcoholism. The Tenth Special Report to the U.S. Congress on Alcohol and Health From the Secretary of Health and Human Services. Washington, DC: National Insitutes of Health; 2000. NIH publication 00-1583.

2. Stinson FS, Dufour MC, Steffens RA, DeBakey TS. Alcohol-related mortality in the United States, 1979-1989. Alcohol Health Res World. 1993; 17:251-260.

3. Hingson RW, Heeren T, Zakocs RC, Kopstein A, Wechsler H. Magnitude of alcohol related mortality and morbidity among uS college students ages 18-24. J Stud Alcohol. 2002;63:136-144.

4. Whitmore CC, Yi HY, Chen CM, Stinson FS, Dufour MC. Surveillance Report \#58 (Revised): Trends in Alcohol-Related Morbidity Among ShortStay Community Hospital Discharges, United States, 1979-99. Bethesda, MD: National Institute on Alcohol Abuse and Alcoholism, Division of Biometry and Epidemiology; 2002.

5. Fleming MF. Brief interventions and the treatment of alcohol use disorders: current evidence. Recent Dev Alcohol. 2003;16:375-390.

6. Wilk Al, Jensen NM, Havighurst TC. Meta-analysis of randomized control trials addressing brief interventions in heavy alcohol drinkers. J Gen Int Med. 1997;12:274-283.

7. Moyer A, Finney JW, Swearingen CE, Vergun P. Brief interventions for alcohol problems: a meta-analytic review of controlled investigations in treatment-seeking and non-treatment-seeking populations. Addiction. 2002;97:279-292.

8. Bertholet N, Daeppen JB, Wietlisbach V, Fleming M, Burnand B. Alcohol brief intervention in primary care: a systematic review. Arch Intern Med, in press.

9. Marlatt GA, Baer JS, Kivlahan DR, et al. Screening and brief intervention for high-risk college student drinkers: results from a 2-year follow-up assessment. J Consul Clinical Psych. 1998;66:604-615.

10. Fleming MF, Barry KL, Manwell LB, Johnson K, London R. Brief physician advice for problem alcohol drinkers: a randomized controlled trial in community-based primary care practices. JAMA. 1997;277:1039-1045.

11. Fleming MF, Mundt MP, French MT, Manwell LB, Stauffacher EA Barry KL. Brief physician advice for problem drinkers: long-term efficacy and benefit-cost analysis. Alcohol Clin Exp Res. 2002;26:36-43.

12. Fleming MF, Barry KL. A three-sample test of a masked alcohol screening questionnaire. Alcohol Alcohol. 1991;26:81-91.

13. Sobell LC, Sobell MB. Timeline follow-back: a technique for assessing self-reported alcohol consumption. In: Litten R, Allen J, eds. Measuring Alcohol Consumption. Totowa, NJ: Human Press; 1992:41-72. 
14. Cochran WG, Cox GM. Experimental Design. 2nd ed. New York, NY: Wiley; 1957.

15. Monti PM, Colby SM, Barnett NP, et al. Brief intervention for harm reduction with alcohol-positive older adolescents in a hospital emergency department. J Consult Clin Psychol. 1999;67:989-994.

16. Bernstein SL, Becker BM. Preventive care in the emergency department: diagnosis and management of smoking and smoking-related illness in the emergency department: a systematic review. Acad Emerg Med. 2002;9:720-729.

17. Silagy C. Physician advice for smoking cessation. Cochrane Database Syst Rev. 2000;CD000165

18. Calfas KJ, Sallis JF, Oldenburg B, French M. Mediators of change in physical activity following an intervention in primary care: PACE. Prev Med. 1997:26:297-304
19. Kamb ML, Fishbein M, Douglas JM Jr, et al. Efficacy of risk-reduction counseling to prevent human immunodeficiency virus and sexually transmitted diseases: a randomized controlled trial. Project RESPECT Study Group. JAMA. 1998:280:1161-1167.

20. Branch WT, Malik TK. Using 'windows of opportunities' in brief interviews to understand patients' concerns. JAMA. 1993;269:16671668.

21. Fiore MC, Fleming MF, Burns ME. Tobacco and Alcohol Abuse: Clinical opportunities for effective intervention. Proc Assoc Am Physicians. 1999;111:131-140.

22. National Institute on Alcohol Abuse and Alcoholism. The Physicians' Guide to Helping Patients with Alcohol Problems. Bethesda, MD: U.S. Department of Health and Human Services, Public Health Service; 2003. NIH Publication 03-3769.

\section{CHANGE-OF-ADDRESS FORM FAMILYY MEDICINE}

Please complete this form and mail to the following address or fax to Annals Circulation at 913-906-6080:

Annals of Family Medicine, Circulation Department, 11400 Tomahawk Creek Pkwy, Leawood, KS 66211-2672

Check if member of sponsoring organization: $\square$ AAFP $\square$ ABFP $\square$ STFM $\square$ ADFM $\square$ AFPRD $\square$ NAPCRG

ID number from label on your journal cover

OLD Information (Please print.)

Name

Company (if applicable)

Address (Street plus Apt or Ste)

City

Country

Telephone

E-Mail
NEW Information (Please print.)

\begin{tabular}{ll}
\hline Name & \\
\hline Company (if applicable) & \\
\hline Address (Street plus Apt or Ste) & State \\
\hline City & Postal Code (9-digit ZIP for US) \\
\hline Country & \\
\hline Telephone & \\
\hline E-Mail &
\end{tabular}

